OPEN ACCESS

Edited by:

Ahmad Jayedi,

Semnan University of Medical

Sciences, Iran

Reviewed by:

Yahya Jalilpiran,

Tehran University of Medical

Sciences, Iran

Hossein Shahinfar,

Iran University of Medical

Sciences, Iran

Asma Kazemi,

Shiraz University of Medical

Sciences, Iran

*Correspondence:

Sakineh Shab-Bidar

s_shabbidar@tums.ac.ir

Specialty section:

This article was submitted to

Nutritional Epidemiology,

a section of the journal

Frontiers in Nutrition

Received: 31 July 2021 Accepted: 24 September 2021 Published: 29 October 2021

Citation:

Bazshahi E, Pourreza S, Imani $H_{\text {, }}$

Azadbakht L, Ebaditabar M Davarzani S, Babaei N, Naghshi S,

Djafarian K and Shab-Bidar S (2021)

The Association of Dietary Energy

Density and Body Composition

Components in a Sample of Iranian

Adults. Front. Nutr. 8:751148.

doi: 10.3389/fnut.2021.751148

\section{The Association of Dietary Energy Density and Body Composition Components in a Sample of Iranian Adults}

\author{
Elham Bazshahi ${ }^{1}$, Sanaz Pourreza ${ }^{1}$, Hossein Imani ${ }^{2}$, Leila Azadbakht ${ }^{1,3,4}$, \\ Mojdeh Ebaditabar ${ }^{1}$, Samira Davarzani ${ }^{1}$, Nadia Babaei ${ }^{1}$, Sina Naghshi ${ }^{2}$, Kurosh Djafarian ${ }^{2}$ \\ and Sakineh Shab-Bidar ${ }^{1 *}$
}

${ }^{1}$ Department of Community Nutrition, School of Nutritional Sciences and Dietetics, Tehran University of Medical Sciences (TUMS), Tehran, Iran, ${ }^{2}$ Department of Clinical Nutrition, School of Nutritional Sciences and Dietetics, Tehran University of Medical Sciences (TUMS), Tehran, Iran, ${ }^{3}$ Diabetes Research Center, Endocrinology and Metabolism Clinical Sciences Institute, Tehran University of Medical Sciences, Tehran, Iran, ${ }^{4}$ Food Security Research Center, School of Nutrition and Food Science, Isfahan University of Medical Sciences, Isfahan, Iran

Background: We aimed to investigate the association between the energy density (ED) of diet and body composition components in Iranian adults.

Methods: We conducted a cross-sectional study on 267 adults in Tehran. We obtained ED ( $\mathrm{kcal} / \mathrm{g})$ using the two most common methods: ED1, ED from foods only with the exclusion of all beverages and ED2, from foods and all beverages. Body composition was measured using a multifrequency bio-impedance analysis. To find a strong association, we used both the linear and binary regression analysis in the three adjusted models.

Results: The mean of ED1 and ED2 was $1.34 \pm 0.23$ and $0.89 \pm 0.20 \mathrm{kcal} / \mathrm{g}$, respectively. Increasing the ED of diet in both methods was associated with a high intake of dietary fat, of saturated fatty acid (SFA), of monounsaturated fatty acid (MUFA), of polyunsaturated fatty acid (PUFA), of oleic and linoleic acids, accompanied by a low intake of fruits, vegetables, and some vitamins and minerals. There was a significant positive relationship between fat-free mass index (FFMI) and ED1 ( $\beta=4.44, p=0.02$ ). However, we found no significant association between the consumption of ED1 and fat mass index (FMI) $(0.28 ; 95 \% \mathrm{Cl} 0.08,0.98 ; p=0.07)$, and abdominal obesity $(0.91$; $95 \% \mathrm{Cl} 0.43,1.94 ; p=0.82)$. Also, ED2 had no association with FMl $(0.86 ; 95 \% \mathrm{Cl}$ $0.26,2.80 ; p=0.81)$ and abdominal obesity $(0.78 ; 95 \% \mathrm{Cl} 0.35,1.72 ; p=0.54)$. No significant associations were found between ED and other anthropometric indices and body composition components after considering the confounders.

Conclusion: This study supports the positive association between ED and poor dietary quality. However, our findings did not show significant associations of dietary energy density (DED) with anthropometric indices and body composition components. Further well-designed studies are required to investigate the exact link between DED and body composition.

\footnotetext{
Keywords: dietary energy density, obesity, waist circumference, body composition, adults
} 


\section{INTRODUCTION}

Measuring body composition, especially energy needs and nutritional status, is very important due to its important clinical applications, particularly in the assessment and management of obesity and its related comorbidities (1). Researchers suggest that abdominal obesity is a better indicator of the risk of chronic diseases such as metabolic syndrome, type 2 diabetes, cardiovascular disease, and mortality (2). The prevalence of abdominal obesity is increasing at an alarming rate around the world (3). Indicators such as percentage body fat (PBF), fat mass index (FMI), and fat-free mass index (FFMI) are more stable in obesity than in body mass index (BMI) or body weight indices (4).

Several studies have examined the role of dietary patterns, food groups, and single nutrients in obesity (5). Recently, much attention has been paid to the energy density (ED) of diet and the etiology of obesity (6). The ED of food can be defined as the amount of metabolizable energy per unit weight of a food $(\mathrm{kJ} / \mathrm{g}$ or $\mathrm{kcal} / \mathrm{g})(7)$ and is obtained by the macronutrient and moisture content of the food. Fat $[2.15 \mathrm{~kJ} / \mathrm{g}(9 \mathrm{kcal} / \mathrm{g})]$ and water $(0 \mathrm{~kJ} / \mathrm{g})$ as most and least energy-dense nutrients are the primary determinants of ED. Dietary energy density (DED) can be defined as the ED of a total diet. No consensus has been reached on the appropriate method for calculating the ED of the diet (8). However, the most commonly used method is to calculate solid foods only, which is believed to better define DED (8-10). In Iran, also among various studies, which have examined the role of ED, the only method used for calculating DED has excluded beverages and considers only solid foods (11-14).

It is often stated that a diet with high ED consumption is significantly associated with a higher risk of overweight and obesity (14). Yin found that ED was positively associated with body composition among Chinese adults (15). This relationship was noted not only in cross-sectional $(10,16)$ and prospective studies $(17,18)$ but also in clinical trials $(19,20)$. In contrast, other studies did not show any significant relationship (21-23).

Previous studies on this topic in the Iranian population have been performed only on women $(12,14,24,25)$ and in a specific age range $(11,25,26)$. On the other hand, these studies examined the association between DED and general obesity and did not consider the relationship for the other components of body composition. Therefore, the main aim of this study was to assess the association between DED and abdominal obesity and FMI among Iranian adults.

\section{SUBJECTS AND METHODS}

\section{Study Population}

Based on the previously calculated correlation coefficient between energy intake and FMI $(r=0.18)$ (15), our target number of participants was $185\left(Z_{1-\frac{\alpha}{2}}+Z_{1-\beta} \times \sqrt{1-r^{2}} / r\right)$. However, to replace patients who were excluded due to underor over-reported food intake, we continued sampling up to enrollement of 276 individuals. This study is a cross-sectional study on apparently healthy adults in Tehran, who had entered the study by a simple and convenience sampling method.
Individuals involved in this study are based on the following inclusion criteria: healthy people who want to participate in this study, both sexes within the age range of 18-59 years, with no history of diabetes, cardiovascular disease or cancer, no pregnant and lactating women, no regular use of a special supplement or drug (slimming, hormonal, sedative, supplements containing thermogenic substances such as caffeine and green tea, linoleic conjugated acid), and the lack of a special diet. After excluding the participants who misreported their daily energy intake, the final analysis was conducted on 267 participants. Participation in this study was completely voluntary and, at the beginning of the study, a consent form was obtained from all participants of the ethical committee of the Tehran University of Medical Sciences (Ethics No.: IR.TUMS.VCR.REC.1396.4085).

\section{Assessment of Dietary Intake}

Nutritional status of individuals was assessed by a 168 -item food frequency questionnaire (FFQ). The reliability and validity of the FFQ for the food group intake have been assessed and found to be acceptable (27). Respondents were asked by trained dietitians to rate their frequency of use in the past year. Depending on the type of food consumption, the frequency of consumption per day, week, and month was questioned. The values for each food item were converted to grams by individuals using the household measures book manual. Also, we calculated the daily nutrient intake for each participant according to the analysis of nutrient contents of all foods using the Nutritionist IV software. For common foods, the approximate proportion of consumption is calculated based on the US Department of Agriculture's national nutrient data bank. The nutrients examined in this study were selected mainly for assessing dietary intake comprehensively while considering the current dietary intake patterns in an Iranian (28).

\section{Calculation of Dietary Energy Density}

To estimate the ED of the diet, the reported amounts of energy (kcal/day) received from foods are divided by total weight of foods (g/day) consumed per day. Because there is currently no standard way to calculate ED, researchers each uses their methods. In this study, we obtained ED using the two most common methods $(8,29)$ : (ED1) ED from foods only (solid, semisolid, and liquid), with the exclusion of all beverages and (ED2) ED from foods and all beverages (carbonated drinks, fruit juices and fruit-flavored drinks, milk, tea, and coffee).

\section{Anthropometric Measurements}

Anthropometric measures, including weight, height, waist, and hip circumference (HC), were measured. The height of participants without shoes was measured by a stadiometer with a sensitivity of $0.1 \mathrm{~cm}$ (Seca, Hamburg, Germany) and the weight using a digital scale (808 Seca, Hamburg, Germany) with an accuracy of $0.1 \mathrm{~kg}$ with light clothing (without coat and raincoat). BMI was calculated by dividing the weight in kilograms by the square of height $\left(\mathrm{kg} / \mathrm{m}^{2}\right)$. WHO classification is commonly used to classify BMI (BMI $\leq 18.5$ was defined as low weight, $18.5-$ 24.9 favorable weight, $25-29.9$ overweight, and $\geq 30$ obese). Waist circumference (WC) was measured between the lower ribs and 
the iliac crest, exhaled. $\mathrm{HC}$ with a tape measure and the waist to hip ratio (WHR) was calculated as WC divided by $\mathrm{HC}$ for each individual. Abdominal obesity was defined as $\mathrm{WC} \geq 102 \mathrm{~cm}$ (40 inches) for men and $\geq 88 \mathrm{~cm}$ ( 35 inches) for women, WHR $>0.9$ for men, and $>0.85$ for women, and waist to height ratio (WHtR) greater than $0 / 5(30)$.

The bioelectric impedance analysis was used to measure body composition components with a commercially available body analyzer (InBody 720, Biospace, Tokyo, Japan). Subjects were hydrated with two glasses of fluids before the measurement. For an accurate measurement, people were advised not to have moderate to vigorous physical activity for $1-2 \mathrm{~h}$ before the analysis and to empty their bladder before the measurement. Also, during the measurement, shoes and socks were removed and clothes were reduced as much as possible. The system provided FMI, FFMI, PBF, total body fat, visceral fat mass, and abdominal fat mass. FMI and FFMI were calculated using the following formulas:

$$
\begin{aligned}
\mathrm{FMI} & =(\text { weight } \times \% \mathrm{BF}) / \text { height }^{2} \\
\mathrm{FFMI} & =[\text { weight }-(\text { weight } \times \% \mathrm{BF})] / \text { height }^{2}
\end{aligned}
$$

\section{Assessment of Other Variables}

According to the inclusion and exclusion criteria, participants were recruited and interviewed to collect general demographic information, including age, marital status (single or married) and lifestyle (alone or with someone), education (under diploma, diploma, or educated), occupation (employee or unemployed), smoking (smoker or non-smoker), disease status (yes or no), supplementation, and medication use (yes or no), using a public information questionnaire. The International Physical Questionnaire (IPAQ) was used to evaluate physical activity (metabolic equivalent; MET.h/day) (31). According to the IPAQ criteria, data were recorded regarding vigorous and moderate activity and walking, for at least $10 \mathrm{~min} /$ day in the last 7 days. The duration and frequency of activity days were multiplied by the MET task value of an activity to calculate an activity. Total physical activity per week was used to calculate the sum of the scores and categorized into three groups: low, moderate, and high. Also, IPAQ was computed for a continuous score and reported as MET-min/week. Participants were asked to recall all their intense and moderate activities last week, along with time taken to complete them. Then, the intensity of each activity (MET) was multiplied by the time it was performed, and finally, these values were added together to determine the value of MET.h/day. Participants were then classified into no or low physical activity, and moderate and high physical activity $(32,33)$.

\section{Statistical Analyses}

Participants were divided based on the tertiles of ED1 and ED2. To compare the general characteristics, anthropometric measurements, body composition, and dietary intake across the tertiles of DEDs, one-way ANOVA and chi-squared tests were used for continuous and categorical variables, respectively. Analysis of covariance (ANCOVA) was used to compare dietary intake among the tertiles of DED by adjusting age, gender, education, occupation, smoking, and physical activity as confounding factors. Based on WHO guidelines, we considered BMI $25-29.9 \mathrm{~kg} / \mathrm{m}^{2}$ to classify overweight, BMI $\geq 30 \mathrm{~kg} / \mathrm{m}^{2}$ as obese, WC $\geq 102 \mathrm{~cm}$ for men and $\geq 88 \mathrm{~cm}$ for women, and WHR $>0.9$ for men and $>0.85$ for women were used as the markers of abdominal obesity (30). Odds ratios (OR) and 95\% CIs were obtained using logistic regression to determine the relationship of ED1 and ED2 with the risk of body composition components including a dichotomous outcome (yes or no) and ED1 and ED2 as exposures. FMI ( $\geq 21.9)$, and FFMI ( $\geq 47.8)$ and PBF $(\geq 30.8)$ were classified into high and low levels using the median.

The risk was reported in the three models (model I: crude; model II: adjusted for age and sex; and model III: adjusted for age, sex, marital status, menopause, physical activity, education, occupation, smoking status, chronic disease, and supplementation). To determine the contribution of anthropometric measurements and body composition components with ED1 and ED2, we used multiple linear regression models (model I: crude; model II: adjusted for age and sex; and model III: adjusted for age, sex, marital status, menopause, physical activity, education, occupation, smoking status, chronic disease, and supplementation). All statistical analyses were performed using the Statistical Package for Social Sciences (version 26; SPSS, Inc., Chicago, IL, USA). The value of $p<0.05$ was considered as a statistical significance level.

\section{RESULTS}

A total of 267 men and women aged 18-59 participated in this cross-sectional study. General characteristics and anthropometric measurements of the participants across the tertiles of ED1 and ED2 are presented in Table 1. More than half of the participants were women, married, educated, nonsmokers, employed, and living with someone. Nine percent of participants had underlying diseases (diabetes, hypertension, or hyperlipidemia). The mean of ED1 and ED2 were $1.34 \pm 0.23$ and $0.89 \pm 0.20$, respectively. The mean age of participants was $36.5 \pm 13.1$. Participants in the highest tertile were significantly older than those in the lowest tertile of ED1 $(p=0.002, p<0.001)$ and ED2 $(p<0.001, p<0.001)$. They also had higher BMI in comparison to those in the lowest tertile of ED1 $(p=0.01, p$ $=0.006)$ and $\operatorname{ED} 2(p=0.002, p<0.001)$. For ED2, WC $(p=$ $0.04, p=0.01)$ and $\mathrm{HC}(p=0.02, p=0.009)$ were significantly different across the tertiles. Meanwhile, WC and HC increased from tertiles 1 to 3 of $\operatorname{ED1}(p=0.04, p=0.02)$, and WHR increased from the first to the last tertile of ED2 $(p=0.03)$, none of them were significantly different $(p=0.12, p=0.07$, and $p=$ 0.08 , respectively). FMI did not differ significantly according to the tertiles of $\operatorname{ED1}(p=0.07)$ and $\operatorname{ED2}(p=0.06)$; however, an increasing trend was detected from the first to the last tertile of both $\operatorname{ED} 1(p=0.03)$ and ED2 $(p=0.02)$. Although energy intake did not have a statistical difference between the tertiles of ED1, it had an increasing trend from the lowest to the highest tertile $(p=0.07, p=0.02)$. Across the tertiles of ED2, energy intake was significantly different $(p=0.009, p=0.01)$. The frequency of obesity during the tertiles of ED2 and abdominal obesity through the tertiles of ED1 were significantly different $(p=0.04$ and 
TABLE 1 | General characteristics of participants by tertiles of the dietary energy density (DED) in a sample of Iranian adults.

\begin{tabular}{|c|c|c|c|c|c|c|c|c|c|c|c|c|c|c|c|c|}
\hline & \multicolumn{6}{|c|}{ Tertiles of dietary energy density (ED1) } & $\begin{array}{c}P \\
\text { value* }^{*}\end{array}$ & $\underset{\text { trend }^{\dagger}}{\mathbf{P}}$ & \multicolumn{6}{|c|}{ Tertiles of dietary energy density (ED2) } & $\begin{array}{c}P \\
\text { value* }\end{array}$ & $\stackrel{P}{\text { trend }^{\dagger}}$ \\
\hline Age (year) & 33.6 & 12.4 & 35.7 & 11.8 & 40.3 & 14.2 & 0.002 & $<0.001$ & 32.0 & 12.2 & 35.7 & 12.1 & 41.9 & 13.1 & $<0.001$ & $<0.001$ \\
\hline Weight (kg) & 70.6 & 14.9 & 72.2 & 16.2 & 74.8 & 16.2 & 0.20 & 0.07 & 69.7 & 17.1 & 73.6 & 15.0 & 74.3 & 15.1 & 0.10 & 0.05 \\
\hline WC (cm) & 87.7 & 12.0 & 89.2 & 11.9 & 91.5 & 13.4 & 0.12 & 0.04 & 87.1 & 13.2 & 89.5 & 11.4 & 91.8 & 12.5 & 0.04 & 0.01 \\
\hline $\mathrm{HC}(\mathrm{cm})$ & 97.6 & 7.18 & 98.4 & 7.35 & 100 & 8.14 & 0.07 & 0.02 & 97 & 7.91 & 99.2 & 7.27 & 99.9 & 7.41 & 0.02 & 0.009 \\
\hline WHR & 0.89 & 0.06 & 0.90 & 0.06 & 0.91 & 0.06 & 0.29 & 0.12 & 0.89 & 0.06 & 0.90 & 0.06 & 0.91 & 0.06 & 0.08 & 0.03 \\
\hline WHtR & 0.52 & 0.06 & 0.53 & 0.06 & 0.54 & 0.08 & 0.03 & 0.01 & 0.51 & 0.06 & 0.53 & 0.06 & 0.55 & 0.07 & 0.03 & 0.001 \\
\hline $\mathrm{FMl}\left(\mathrm{kg} / \mathrm{m}^{2}\right)$ & 21.3 & 8.68 & 21.5 & 7.46 & 24.2 & 11.4 & 0.07 & 0.03 & 20.9 & 9.17 & 22.1 & 9.23 & 24.1 & 9.68 & 0.06 & 0.02 \\
\hline FFMI $\left(\mathrm{kg} / \mathrm{m}^{2}\right)$ & 49.2 & 11.6 & 50.7 & 13.3 & 50.5 & 11.4 & 0.67 & 0.48 & 48.8 & 12.8 & 51.5 & 12.8 & 50.1 & 10.5 & 0.35 & 0.47 \\
\hline Overweight (\%) § & 27.0 & & 24.7 & & 29.2 & & 0.10 & & 22.5 & & 30.3 & & 28.1 & & 0.06 & \\
\hline $\begin{array}{l}\text { Abdominal } \\
\text { obesity (\%) \|| }\end{array}$ & 23.8 & & 15.2 & & 35.8 & & 0.01 & & 21.0 & & 24.7 & & 29.5 & & 0.46 & \\
\hline \multicolumn{17}{|l|}{ Gender (\%) } \\
\hline Male & 44.9 & & 47.2 & & 39.3 & & 0.55 & & 39.3 & & 47.2 & & 44.9 & & 0.55 & \\
\hline Female & 55.1 & & 52.8 & & 60.7 & & & & 60.7 & & 52.8 & & 55.1 & & & \\
\hline \multicolumn{17}{|l|}{ Education (\%) } \\
\hline Under diploma & 4.5 & & 5.6 & & 12.4 & & 0.26 & & 5.6 & & 7.9 & & 10.1 & & 0.69 & \\
\hline Diploma & 15.7 & & 19.1 & & 20.2 & & & & 16.9 & & 16.9 & & 21.3 & & & \\
\hline Educated & 78.7 & & 75.3 & & 67.4 & & & & 77.5 & & 75.3 & & 68.5 & & & \\
\hline \multicolumn{17}{|l|}{ Occupation (\%) } \\
\hline Yes & 7.9 & & 9.0 & & 23.6 & & 0.01 & & 10.1 & & 11.2 & & 19.1 & & 0.19 & \\
\hline No & 47.2 & & 43.8 & & 37.1 & & & & 50.6 & & 41.6 & & 36.0 & & & \\
\hline Disease status & & & & & & & & & & & & & & & & \\
\hline Yes & 6.7 & & 10.1 & & 10.2 & & 65.0 & & 2.2 & & 10.2 & & 14.6 & & 0.01 & \\
\hline No & 93.3 & & 89.9 & & 89.8 & & & & 97.8 & & 89.8 & & 85.4 & & & \\
\hline Lifestyle (\%) & & & & & & & & & & & & & & & & \\
\hline Alone & 7.9 & & 7.9 & & 11.2 & & 0.66 & & 9.0 & & 12.4 & & 5.6 & & 0.29 & \\
\hline With someone & 92.1 & & 92.1 & & 88.8 & & & & 91.0 & & 87.6 & & 94.4 & & & \\
\hline Smoking (\%) & & & & & & & & & & & & & & & & \\
\hline Smoker & 13.5 & & 12.4 & & 14.6 & & 0.90 & & 6.7 & & 16.9 & & 16.9 & & 0.07 & \\
\hline No smoker & 86.5 & & 87.6 & & 85.4 & & & & 93.3 & & 83.1 & & 83.1 & & & \\
\hline $\begin{array}{l}\text { Physical activity } \\
\text { (\%) }\end{array}$ & & & & & & & & & & & & & & & & \\
\hline Low & 40.4 & & 39.3 & & 34.8 & & 0.73 & & 46.1 & & 34.8 & & 33.7 & & 0.08 & \\
\hline Moderate & 40.4 & & 43.8 & & 40.4 & & & & 30.3 & & 43.8 & & 50.6 & & & \\
\hline High & 19.1 & & 16.9 & & 24.7 & & & & 23.6 & & 21.3 & & 15.7 & & & \\
\hline
\end{tabular}

ED1, energy density from foods only; ED2, energy density from foods and all beverages; SD, standard deviation; BMI, body mass index; WC, waist circumference; HC, hip circumference; WHR, waist to hip ratio; FMI, fat mass index $=$ (weight $\times$ PBF)/height; FFMI, fat-free mass index = [weight - (weight $\times$ PBF)]/height; PBF, percentage body fat calculated using sexspecific equations. Data are presented as means and SD. ${ }^{*} p$-values result from ANOVA for quantitative variables and $\chi 2$ test for qualitative variables. ${ }^{\dagger} p$-values for trend analysis by using linear regression. ${ }^{\ddagger}$ Obesity: BMI $\geq 30.0 \mathrm{~kg} / \mathrm{m}^{2}$. \$Overweight: BMI $25-29.9 \mathrm{~kg} / \mathrm{m}^{2}$. ||Abdominal obesity: defined as $W C \geq 102 \mathrm{~cm}$ for men and $\geq 88 \mathrm{~cm}$ for women. p-value is considered significant at $<0.05$. 
TABLE 2 | Dietary intake of Iranian adults by tertiles of DED.

\begin{tabular}{|c|c|c|c|c|c|c|c|c|c|c|c|c|c|c|c|c|}
\hline & \multicolumn{6}{|c|}{ Tertiles of dietary energy density (ED1) } & \multirow{3}{*}{$\begin{array}{c}P \\
\text { trend }^{*}\end{array}$} & \multirow{3}{*}{$\begin{array}{c}P \\
\text { value }^{\dagger}\end{array}$} & \multicolumn{6}{|c|}{ Tertiles of dietary energy density (ED2) } & \multirow{3}{*}{$\begin{array}{c}P \\
\text { trend* }\end{array}$} & \multirow{3}{*}{$\underset{\text { value }^{\dagger}}{P}$} \\
\hline & \multicolumn{2}{|c|}{$\begin{array}{c}\mathrm{T} 1(n=89) \\
0.66-1.11 \mathrm{kcal} / \mathrm{g}\end{array}$} & \multicolumn{2}{|c|}{$\begin{array}{c}\text { T2 }(n=89) \\
1.11-1.56 \mathrm{kcal} / \mathrm{g}\end{array}$} & \multicolumn{2}{|c|}{$\begin{array}{c}\text { T3 }(n=89) \\
1.56-2.02 \mathrm{kcal} / \mathrm{g}\end{array}$} & & & \multicolumn{2}{|c|}{$\begin{array}{c}\mathrm{T} 1(n=89) \\
0.38-0.76 \mathrm{kcal} / \mathrm{g}\end{array}$} & \multicolumn{2}{|c|}{$\begin{array}{c}\text { T2 }(n=89) \\
0.76-1.14 \mathrm{kcal} / \mathrm{g}\end{array}$} & \multicolumn{2}{|c|}{$\begin{array}{c}\text { T3 }(n=89) \\
1.14-1.52 \mathrm{kcal} / \mathrm{g}\end{array}$} & & \\
\hline & Mean & SD & Mean & SD & Mean & SD & & & Mean & SD & Mean & SD & Mean & SD & & \\
\hline \multicolumn{17}{|l|}{ Nutrients } \\
\hline $\begin{array}{l}\text { Total energy } \\
\text { (kcal/d) }\end{array}$ & 2,190 & 660 & 2,262 & 766 & 2,433 & 734 & 0.02 & 0.01 & 2,102 & 742 & 2,401 & 710 & 2,382 & 695 & 0.01 & $<0.001$ \\
\hline $\begin{array}{l}\text { Carbohydrate } \\
\text { (g/d) }\end{array}$ & 321 & 100 & 326 & 120 & 334 & 120 & 0.45 & 0.33 & 309 & 118 & 346 & 110 & 326 & 110 & 0.31 & 0.003 \\
\hline Protein (g/d) & 89.1 & 33.5 & 85.3 & 40.8 & 88.3 & 30.5 & 0.89 & 0.68 & 79.9 & 29.8 & 96.9 & 41.8 & 85.9 & 30.6 & 0.24 & 0.001 \\
\hline Fat $(\mathrm{g} / \mathrm{d})$ & 67.0 & 26.8 & 74 & 27.6 & 87 & 33.4 & $<0.001$ & $<0.001$ & 65.8 & 27.4 & 75.9 & 27.4 & 86.4 & 33.1 & $<0.001$ & $<0.001$ \\
\hline SFA (g/d) & 20.0 & 0.14 & 22.2 & 8.70 & 27.2 & 11.8 & $<0.001$ & $<0.001$ & 20.2 & 9.75 & 23.6 & 9.95 & 25.6 & 10.8 & $<0.001$ & 0.001 \\
\hline MUFA (g/d) & 19.3 & 8.67 & 22.0 & 10.0 & 26.7 & 11.7 & $<0.001$ & $<0.001$ & 19.1 & 8.71 & 22.4 & 10 & 26.4 & 11.8 & $<0.001$ & $<0.001$ \\
\hline PUFA (g/d) & 14.0 & 7.28 & 15.4 & 8.18 & 18.8 & 10.1 & $<0.001$ & 0.002 & 13.8 & 7.78 & 14.7 & 6.50 & 19.7 & 10.6 & $<0.001$ & $<0.001$ \\
\hline n9-oleic (g/d) & 17.2 & 8.77 & 18.8 & 8.58 & 22.1 & 10.7 & 0.001 & 0.002 & 16.1 & 7.61 & 19.2 & 8.82 & 22.7 & 10.9 & $<0.001$ & $<0.001$ \\
\hline n6-linoleic (g/d) & 11.5 & 6.74 & 13.3 & 7.71 & 16.2 & 9.46 & $<0.001$ & 0.002 & 11.6 & 7.35 & 12.3 & 5.98 & 17.1 & 9.89 & $<0.001$ & $<0.001$ \\
\hline n3-linolenic (g/d) & 0.11 & 0.08 & 0.12 & 0.08 & 0.16 & 0.13 & $<0.001$ & 0.001 & 0.12 & 0.09 & 0.13 & 0.10 & 0.14 & 0.11 & 0.15 & 0.15 \\
\hline EPA (g/d) & 0.03 & 0.05 & 0.03 & 0.03 & 0.02 & 0.03 & 0.16 & 0.34 & 0.03 & 0.05 & 0.03 & 0.03 & 0.02 & 0.03 & 0.1 & 0.32 \\
\hline $\mathrm{DHA}(\mathrm{g} / \mathrm{d})$ & 0.08 & 0.12 & 0.07 & 0.08 & 0.06 & 0.07 & 0.16 & 0.34 & 0.08 & 0.13 & 0.07 & 0.08 & 0.06 & 0.07 & 0.1 & 0.32 \\
\hline $\begin{array}{l}\text { Cholesterol } \\
(\mathrm{mg} / \mathrm{d})\end{array}$ & 309 & 240 & 275 & 198 & 280 & 137 & 0.32 & 0.18 & 263 & 148 & 326 & 236 & 276 & 192 & 0.67 & 0.18 \\
\hline $\begin{array}{l}\text { Dietary fiber } \\
(\mathrm{g} / \mathrm{d})\end{array}$ & 18.1 & 6.56 & 15.1 & 6.75 & 13.5 & 5.01 & $<0.001$ & $<0.001$ & 15.9 & 7.21 & 16.7 & 6.50 & 14.2 & 5.20 & 0.07 & 0.09 \\
\hline $\mathrm{Na}(\mathrm{mg} / \mathrm{d})$ & 4,284 & 2,548 & 4,105 & 2,452 & 4,480 & 2,536 & 0.60 & 0.64 & 4,201 & 2,808 & 4,296 & 2,105 & 4,372 & 2,584 & 0.65 & 0.85 \\
\hline $\mathrm{K}(\mathrm{mg} / \mathrm{d})$ & 3,970 & 1,402 & 3,379 & 1,323 & 3,040 & 1,098 & $<0.001$ & $<0.001$ & 3,637 & 1,392 & 3,702 & 1,395 & 3,051 & 1,107 & 0.003 & 0.05 \\
\hline $\mathrm{Ph}(\mathrm{mg} / \mathrm{d})$ & 1,361 & 553 & 1,253 & 570 & 1,217 & 456 & 0.07 & 0.17 & 1,258 & 546 & 1,375 & 576 & 1,197 & 451 & 0.44 & 0.19 \\
\hline Se (mg/d) & 0.03 & 0.02 & 0.04 & 0.03 & 0.04 & 0.02 & 0.21 & 0.45 & 0.03 & 0.2 & 0.04 & 0.03 & 0.04 & 0.03 & 0.15 & 0.14 \\
\hline $\mathrm{Mg}(\mathrm{mg} / \mathrm{d})$ & 306 & 101 & 274 & 104 & 256 & 86.4 & 0.001 & 0.01 & 287 & 106 & 296 & 103 & 253 & 83.2 & 0.01 & 0.12 \\
\hline $\mathrm{Fe}(\mathrm{mg} / \mathrm{d})$ & 21.5 & 10 & 21.2 & 10.7 & 19.8 & 6.89 & 0.23 & 0.48 & 18.8 & 8.33 & 23.4 & 11.6 & 20.2 & 6.86 & 0.31 & 0.002 \\
\hline $\mathrm{Ca}(\mathrm{mg} / \mathrm{d})$ & 1,103 & 526 & 950 & 454 & 923 & 374 & 0.009 & 0.05 & 1,017 & 521 & 1,069 & 485 & 889 & 343 & 0.06 & 0.16 \\
\hline Zn (mg/d) & 9.85 & 4.01 & 9.19 & 4.42 & 9.13 & 3.25 & 0.21 & 0.35 & 8.73 & 3.58 & 10.3 & 4.65 & 9.12 & 3.26 & 0.5 & 0.01 \\
\hline Vitamin A (mg/d) & 1,723 & 1,294 & 1,206 & 676 & 1,090 & 717 & $<0.001$ & $<0.001$ & 1,398 & 1,191 & 1,391 & 821 & 1,230 & 875 & 0.25 & 0.85 \\
\hline Vitamin E (mg/d) & 4.79 & 2.77 & 4.20 & 2.49 & 3.76 & 1.79 & 0.004 & 0.02 & 4.07 & 2.31 & 4.7 & 3.0 & 3.98 & 1.62 & 0.8 & 0.11 \\
\hline Vitamin D (mg/d) & 2.46 & 2.07 & 2.12 & 2.33 & 2.14 & 1.80 & 0.31 & 0.43 & 2.38 & 2.14 & 2.63 & 2.53 & 1.73 & 1.27 & 0.03 & 0.02 \\
\hline Folate (mg/d) & 347 & 138 & 290 & 126 & 274 & 110 & $<0.001$ & 0.002 & 330 & 139 & 311 & 123 & 270 & 116 & 0.002 & 0.17 \\
\hline Vitamin B1 (mg/d) & 1.80 & 0.62 & 1.76 & 0.63 & 1.81 & 0.68 & 0.90 & 0.7 & 1.67 & 0.66 & 1.91 & 0.63 & 1.78 & 0.62 & 0.25 & 0.003 \\
\hline Vitamin B2 (mg/d) & 1.80 & 0.81 & 1.59 & 0.77 & 1.62 & 0.63 & 0.11 & 0.11 & 1.64 & 0.78 & 1.79 & 0.80 & 1.58 & 0.64 & 0.59 & 0.31 \\
\hline Vitamin B3 (mg/d) & 20.98 & 7.27 & 21.1 & 9.45 & 22.3 & 7.91 & 0.25 & 0.3 & 19.0 & 7.74 & 23.4 & 9.07 & 22 & 7.32 & 0.01 & $<0.001$ \\
\hline Vitamin B5 (mg/d) & 6.59 & 2.52 & 5.81 & 2.65 & 5.15 & 1.82 & $<0.001$ & $<0.001$ & 5.89 & 2.59 & 6.23 & 2.51 & 5.43 & 2.10 & 0.19 & 0.33 \\
\hline Vitamin B6 (mg/d) & 1.66 & 0.70 & 1.39 & 0.69 & 1.28 & 0.52 & $<0.001$ & 0.001 & 1.38 & 0.61 & 1.57 & 0.69 & 1.37 & 0.65 & 0.92 & 0.05 \\
\hline $\begin{array}{l}\text { Vitamin B12 } \\
(\mathrm{mg} / \mathrm{d})\end{array}$ & 4.74 & 2.90 & 4.16 & 2.33 & 4.47 & 2.73 & 0.50 & 0.17 & 4.27 & 2.4 & 4.9 & 2.86 & 4.2 & 2.68 & 0.87 & 0.32 \\
\hline Vitamin C (mg/d) & 181 & 82.1 & 128 & 61.7 & 97.8 & 42.7 & $<0.001$ & $<0.001$ & 143 & 74.4 & 149 & 82 & 115 & 55.6 & 0.009 & 0.05 \\
\hline Biotin (mg/d) & 30.2 & 15.1 & 25.6 & 10.9 & 23.3 & 10 & $<0.001$ & $<0.001$ & 26.2 & 11.7 & 29 & 14.7 & 23.9 & 10.3 & 0.21 & 0.06 \\
\hline Sugar (g/d) & 93.9 & 37.5 & 84.1 & 41.4 & 73 & 32.7 & $<0.001$ & 0.009 & 87.9 & 42.4 & 88.1 & 37.7 & 75 & 32.8 & 0.02 & 0.35 \\
\hline \multicolumn{17}{|l|}{$\begin{array}{l}\text { Food groups } \\
\text { (g/d) }\end{array}$} \\
\hline Fruits & 385 & 193 & 293 & 188 & 213 & 123 & $<0.001$ & $<0.001$ & 293 & 167 & 344 & 220 & 255 & 150 & 0.16 & 0.007 \\
\hline Vegetables & 513 & 257 & 335 & 162 & 261 & 134 & $<0.001$ & $<0.001$ & 431 & 260 & 368 & 199 & 311 & 173 & $<0.001$ & 0.17 \\
\hline Red meat & 40.2 & 29 & 43.6 & 35.6 & 50.7 & 46.5 & 0.06 & 0.19 & 33.8 & 25.4 & 54.5 & 44.7 & 46.2 & 38.2 & 0.02 & 0.001 \\
\hline $\begin{array}{l}\text { White meat and } \\
\text { fish }\end{array}$ & 73.9 & 65.3 & 73.4 & 85.3 & 69.9 & 52.2 & 0.69 & 0.79 & 60.6 & 48.8 & 85.3 & 87.9 & 71.3 & 62.0 & 0.3 & 0.06 \\
\hline Grains & 418 & 238 & 447 & 205 & 448 & 193 & 0.34 & 0.54 & 400 & 217 & 474 & 224 & 439 & 190 & 0.21 & 0.01 \\
\hline Dairy & 525 & 373 & 449 & 287 & 409 & 247 & 0.01 & 0.04 & 503 & 361 & 501 & 327 & 380 & 207 & 0.008 & 0.04 \\
\hline Nuts & 11.5 & 10.6 & 14 & 19 & 11.1 & 10.9 & 0.85 & 0.34 & 11.8 & 15.1 & 11.3 & 14.4 & 13.4 & 12.6 & 0.44 & 0.21 \\
\hline Legumes & 31.6 & 33.6 & 29.9 & 35.9 & 36.7 & 33.8 & 0.32 & 0.49 & 30.1 & 34.2 & 36.4 & 40.3 & 31.6 & 27.6 & 0.76 & 0.55 \\
\hline
\end{tabular}

ED1, energy density from foods only; ED2, energy density from foods and all beverages; SD, standard deviation. Data are presented as means and SD. ${ }^{*} P$ values for trend result from ANOVA using linear regression. ${ }^{\dagger}$ Obtained from analysis of covariance (ANCOVA) test adjusted by age, gender, education, occupation, physical activity, and smoking. 
$p=0.01$, respectively). Among the demographic characteristics, marital status was significantly different among the tertiles of $\operatorname{ED} 1(p=<0.001)$ and ED2 $(p<0.001)$.

Table 2 presents the dietary intake of nutrients and food groups among the tertiles of DED. There were significant differences in total energy intake, fat, saturated fatty acid (SFA), monounsaturated fatty acid (MUFA), polyunsaturated fatty acid (PUFA), oleic acid, linoleic and linolenic acids, soluble and insoluble fiber consumption among the tertiles of ED1. All of them remained significant after adjusting for age, gender, education, occupation, physical activity, and smoking as covariates. Participants in the highest tertile had more total energy and fat intake ( $p=0.02$ and $p<0.001$, respectively), and a lower intake of dietary fiber $(p<0.001)$. Among vitamins and minerals, significant differences were observed for potassium $(\mathrm{K})$, magnesium $(\mathrm{Mg})$, calcium $(\mathrm{Ca})$, vitamin $\mathrm{A}$, vitamin $\mathrm{E}$, folate, vitamins B5 and B6, vitamin C, and biotin. Only Ca intake was not significant across the tertiles of DED after an adjustment for covariates. Moreover, sugar consumption was significantly different across the tertiles of ED1 $(p<0.001)$. Individuals of the last tertile had a lower amount of sugar consumption. Among the main food groups, the differences were significant for fruits, vegetables, and dairy $(p<0.001, p<0.001$, and $p=$ 0.01 , respectively).

People at the last tertile of ED2 had a greater intake of fat, SFA, MUFA, PUFA, oleic acid, linoleic and linolenic acids, sodium $(\mathrm{Na})$, and nuts. Total energy intake, fat, SFA, MUFA, PUFA, oleic acid, linoleic acid, and insoluble fiber were statistically different among the tertiles of ED2. However, the consumption of carbohydrates and protein was significant only after the adjustment of covariates ( $p=0.003$ and $p=0.001$, respectively). Statistical differences were noted for $\mathrm{K}, \mathrm{Mg}$, vitamin $\mathrm{D}$, folate, vitamin $\mathrm{B}$ 3, vitamin $\mathrm{C}$, and sugar consumption. Only vitamin $\mathrm{D}$ and vitamin $\mathrm{B} 3$ remained significantly different after the adjustment. After adjusting for covariates, the intake of iron $(\mathrm{Fe})$, zinc $(\mathrm{Zn})$, and vitamin $\mathrm{B} 1$ turns out to be significantly different across the tertiles $(p=0.002, p=0.01$, and $p=$ 0.003 , respectively). In terms of the main food groups, the intake of vegetables, red meat, and dairy had significant differences among the tertiles of $\operatorname{ED2}(p<0.001, p=0.02$, and $p=$ 0.008 , respectively). Participants of the first tertiles consumed higher amounts of fruits and dairy and lower amounts of red meat. Unlike vegetables, the intake of fruits and grains became statistically different after adjusting for covariates $(p=0.007$ and $p=0.01$, respectively).

The association between DED and obesity measures is shown in Table 3. BMI $(\beta=2.95, p=0.01)$, WC $(\beta=6.67, p=0.04)$, and WHtR $(\beta=0.04, p=0.03)$ showed significant positive associations with ED1 in the crude model. A significant positive relationship was observed between FFM and ED1 after adjusting for covariates in the first and second model $(\beta=4.44, p=0.02)$ and $(\beta=4.19, p=0.04)$, respectively. Also, we found a straight association between ED2 with BMI ( $\beta=3.23, p=0.01)$ and WHtR ( $\beta=0.04, p=0.02)$. These results were not significant after controlling for covariates.

Odds ratios and $95 \%$ CI for body composition components in the tertile of DED are presented in Table 4. No significant relationship was observed between ED with FMI, WC and other anthropometric indices, and body composition components after the control of confounders in the first and second model. However, during ED1 tertiles, overweight in the crude model and FFM in the second model had a significant decreasing effect $(p=$ $0.03)(p=0.04)$, respectively.

\section{DISCUSSION}

The results of this study failed to show any significant association between DED, which allowed to calculate ED in the two most common different ways (ED1, using the foods only and ED2, which considering foods and all beverages) with abdominal obesity and body fat mass. Our findings showed an only significant positive correlation between ED1 and FFM after the control of confounders. We also found that there was no association between DED and odds of body composition components. To our knowledge, this is the first study to research the association between the DED, both with and without the inclusion of beverages, with abdominal obesity as measured by $\mathrm{WC}$ and FMI in the Iranian population.

Despite an increase in epidemiological studies on DED, there is still no standard method for calculating it. The most common method is to eliminate drinks. This is because it is well known that drinking has a weak and different effect on controlling and regulating appetite and satiety, and the inclusion of beverages in the DED calculation can change the interpretation of findings $(34,35)$. As a result, the consumption of beverages should not be ignored because the energy that individuals get from consuming drinks can affect the obesity process. That is why Johnson et al. (8) suggests that the energy received from beverages should be considered as a covariate in DED analyses.

Evidence from previous observational studies on the association between ED and body composition is conflicting. In line with our findings, Van Sluijs et al. (36) in a prospective study found no association between DED from foods only with FMI and PBF at baseline or follow-up, and the only positive association between DED and WC was at baseline but not at follow-up. Marchioni et al. (37) showed no association between the ED of foods and anthropometric variables. Also, a study using the data from the China Health and Nutrition Surveys (CHNS) showed a null link between ED, including beverages, and body composition (38). In addition, de Castro reported that ED from foods only (21) and foods and beverages (23) were not significantly related to body size, height, weight, or BMI.

Contrary to our findings, a cohort study by Sasaki et al. (39) concluded that the association between the ED of foods only and body weight gain was stronger in men with normal weight but in women, the association between ED and weight change was not statistically significant. Murakami et al. (40) reported that a lower DED from foods was positively associated with a lower prevalence of abdominal obesity $(\mathrm{WC} \geq 80 \mathrm{~cm}$ ) in women but not in men. Du et al. (41), in their multicenter prospective cohort study, observed that a diet with higher ED from foods only was not associated with weight change but was positively associated with WC change. Yin et al. (15) 
TABLE 3 | Multiple regression analysis models exploring the association of DED with WC, FMI, and body composition components in a sample of Iranian adults.

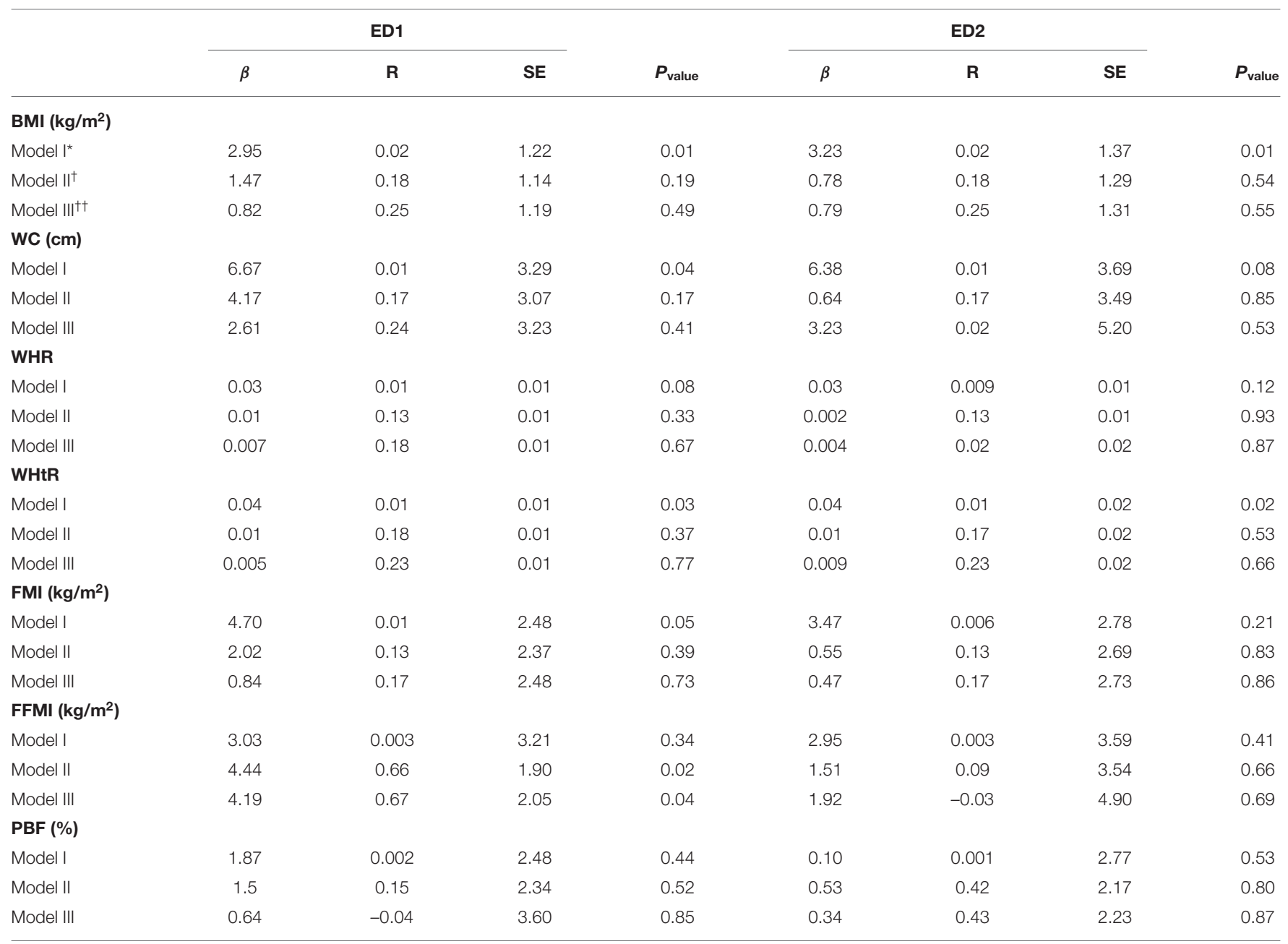

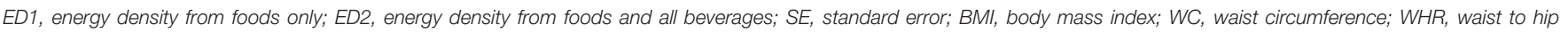

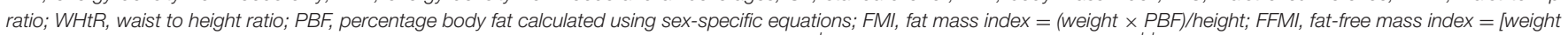

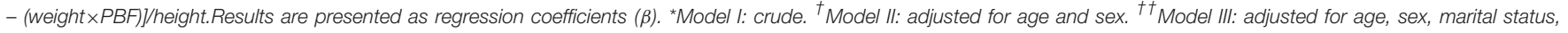
menopause, physical activity, education, occupation, smoking status, chronic disease, and supplementation. $p<0.05$ was considered significant.

who explored the link between ED through five methods and body composition components among Chinese adults found that all ED definitions were positively associated to higher increases of body composition among women than in men. Correa et al. (42) also revealed that the associations between DED from foods and BMI, FMI, and fat mass percent were statistically significant in young adults aged $18-25$ years. The results of these studies are the same as those found in the published systematic reviews and meta-analyses, which have concluded that there is a significant relationship between the ED of food and BMI $(43,44)$. In addition, a systematic review in children and adolescents as well as in adult, also supports a relationship between ED and body weight (45). Similarly, another cohort study demonstrated that weight gain was positively related to greater DED during a 6-year follow-up in overweight subjects (46). Therefore, these studies support the hypothesis that reducing DED can be a useful strategy for controlling body weight. These discrepant findings may be explained by a series of methodological issues like ethnic and socioeconomic differences and by the method of dietary assessment in studies. All self-reported dietary assessment methods are subject to both random and systematic measurement errors (47). Given a day-to-day variation in the dietary intake of individuals, the estimates of dietary intake derived from a dietary record used in some studies $(40,48)$ unlikely represent the usual intake of individuals. For this reason, we used a validated FFQ for dietary assessment, which reflects an individual's long-term habitual dietary intake. Furthermore, the underreporting of energy intake during these research studies is a problem that has to be considered $(21,38)$. On the other hand, gender differences that affect body composition should not be ignored. Another reason for conflicting results is due to a variation within the definitions of ED. Because DED considers all foods together, it provides a general definition of diet. For this reason, DED in each population has its characteristics that can affect the final results. Therefore, in different populations with respective dietary 
TABLE 4 | Multivariable-adjusted odds ratios (OR) and 95\% Cls of WC, FMI, and body composition components according to tertiles of DED in a sample of Iranian adults.

\begin{tabular}{|c|c|c|c|c|c|c|c|c|c|c|c|c|}
\hline & \multicolumn{6}{|c|}{ ED1 } & \multicolumn{6}{|c|}{ ED2 } \\
\hline & \multirow{3}{*}{$\begin{array}{c}\mathrm{T} 1 \\
0.66-1.11 \\
\mathrm{kcal} / \mathrm{g}\end{array}$} & \multirow[t]{3}{*}{$\boldsymbol{P}_{\text {value }}$} & \multirow{2}{*}{$\begin{array}{c}\mathrm{T} 2 \\
1.11-1.56 \mathrm{kcal} / \mathrm{g} \\
\end{array}$} & \multirow[t]{3}{*}{$P_{\text {value }}$} & \multirow{2}{*}{$\begin{array}{c}\text { T3 } \\
1.56-2.02 \mathrm{kcal} / \mathrm{g}\end{array}$} & \multirow[t]{3}{*}{$P_{\text {value }}$} & \multirow{3}{*}{$\begin{array}{c}\mathrm{T} 1 \\
0.38-0.76 \\
\mathrm{kcal} / \mathrm{g}\end{array}$} & \multirow[t]{3}{*}{$P_{\text {value }}$} & \multirow{3}{*}{$\begin{array}{c}\text { T2 } \\
\frac{0.76-1.14 \mathrm{kcal} / \mathrm{g}}{\text { OR }(95 \% \mathrm{Cl})}\end{array}$} & \multirow[t]{3}{*}{$P_{\text {value }}$} & T3 & \multirow[t]{3}{*}{$P_{\text {value }}$} \\
\hline & & & & & & & & & & & $1.14-1.52 \mathrm{kcal} / \mathrm{g}$ & \\
\hline & & & OR (95 \% Cl) & & OR (95 \% Cl) & & & & & & OR (95 \% Cl) & \\
\hline \multicolumn{13}{|l|}{ Obese $^{\ddagger}$} \\
\hline Model I* & 1 & 0.05 & $2.29(1.00,5.22)$ & 0.04 & $1.00(0.39,2.53)$ & 1.00 & 1 & 0.05 & $0.48(0.21,1.08)$ & 0.07 & $0.38(0.16,0.90)$ & 0.02 \\
\hline Model II & 1 & 0.36 & $0.56(0.23,1.35)$ & 0.19 & $0.62(0.25,1.50)$ & 0.29 & 1 & 0.54 & $0.67(0.28,1.57)$ & 0.36 & $0.65(0.26,1.61)$ & 0.35 \\
\hline Model III†† & 1 & 0.70 & $0.70(0.26,1.86)$ & 0.48 & $0.68(0.24,1.92)$ & 0.47 & 1 & 0.84 & $0.75(0.29,1.94)$ & 0.56 & $0.81(0.27,2.41)$ & 0.71 \\
\hline \multicolumn{13}{|c|}{$\begin{array}{l}\text { Overweight } \\
\S\end{array}$} \\
\hline Model I & 1 & 0.09 & $2.04(1.05,3.94)$ & 0.13 & $1.24(0.65,2.36)$ & 0.03 & 1 & 0.009 & $0.89(0.47,1.71)$ & 0.74 & $0.38(0.19,0.74)$ & 0.005 \\
\hline Model II & 1 & 0.31 & $0.67(0.34,1.33)$ & 0.25 & $0.59(0.29,1.19)$ & 0.14 & 1 & 0.08 & $1.06(0.53,2.10)$ & 0.85 & $0.51(0.25,1.06)$ & 0.07 \\
\hline Model III & 1 & 0.50 & $0.85(0.39,1.86)$ & 0.69 & $0.63(0.28,1.40)$ & 0.26 & 1 & 0.28 & $0.96(0.45,2.07)$ & 0.93 & $0.55(0.23,1.27)$ & 0.16 \\
\hline \multicolumn{13}{|l|}{$\begin{array}{l}\text { Abdominal } \\
\text { obesity \| }\end{array}$} \\
\hline Model I & 1 & 0.42 & $1.79(0.90,3.55)$ & 0.29 & $0.57(0.25,1.28)$ & 0.23 & 1 & 0.05 & $1.57(0.76,3.24)$ & 0.45 & $1.23(0.59,2.57)$ & 0.01 \\
\hline Model II & 1 & 0.67 & $0.39(0.16,0.96)$ & 0.40 & $0.79(0.34,1.85)$ & 0.51 & 1 & 0.47 & $1.08(0.46,2.55)$ & 0.85 & $0.81(0.33,1.94)$ & 0.63 \\
\hline Model III & 1 & 0.97 & $0.98(0.47,2.04)$ & 0.96 & $0.91(0.43,1.94)$ & 0.82 & 1 & 0.83 & $0.89(0.43,1.83)$ & 0.75 & $0.78(0.35,1.72)$ & 0.54 \\
\hline \multicolumn{13}{|l|}{ WHR } \\
\hline Model I & 1 & 0.52 & $0.76(0.42,1.37)$ & 0.36 & $0.72(0.40,1.31)$ & 0.29 & 1 & 0.05 & $0.75(0.41,1.37)$ & 0.36 & $0.48(0.26,0.87)$ & 0.01 \\
\hline Model II & 1 & 0.92 & $0.88(0.46,1.67)$ & 0.7 & $0.95(0.5,1.82)$ & 0.89 & 1 & 0.68 & $0.98(0.51,1.88)$ & 0.96 & $0.77(0.39,1.50)$ & 0.44 \\
\hline Model III & 1 & 0.87 & $1.13(0.54,2.36)$ & 0.73 & $1.21(0.57,2.58)$ & 0.61 & 1 & 0.99 & $1.03(0.50,2.12)$ & 0.92 & $0.99(0.46,2.17)$ & 0.99 \\
\hline \multicolumn{13}{|l|}{ WHtR } \\
\hline Model I & 1 & 0.07 & $1.97(1.08,3.58)$ & 0.02 & $1.25(0.69,2.27)$ & 0.45 & 1 & 0.003 & $0.60(0.33,1.09)$ & 0.09 & $0.34(0.18,0.63)$ & 0.001 \\
\hline Model II & 1 & 0.56 & $0.79(0.42,1.51)$ & 0.49 & $0.70(0.36,1.35)$ & 0.29 & 1 & 0.22 & $0.83(0.44,1.59)$ & 0.58 & $0.56(0.28,1.09)$ & 0.09 \\
\hline Model III & 1 & 0.79 & $1.03(0.49,2.16)$ & 0.93 & $0.81(0.37,1.76)$ & 0.60 & 1 & 0.36 & $0.80(0.38,1.66)$ & 0.55 & $0.56(0.25,1.24)$ & 0.15 \\
\hline \multicolumn{13}{|c|}{ FMI (kg/m2) } \\
\hline Model I & 1 & 0.94 & $0.95(0.53,1.72)$ & 1.00 & $0.87(0.48,1.57)$ & 0.76 & 1 & 0.62 & $0.95(0.53,1.72)$ & 0.88 & $0.76(0.42,1.37)$ & 0.36 \\
\hline Model II & 1 & 0.18 & $0.41(0.13,1.21)$ & 0.57 & $0.39(0.13,1.17)$ & 0.24 & 1 & 84.0 & $0.72(0.25,2.1)$ & 0.55 & $0.85(0.29,2.45)$ & 0.76 \\
\hline Model III & 1 & 0.17 & $0.35(0.10,1.19)$ & 0.13 & $0.28(0.08,0.98)$ & 0.07 & 1 & 0.71 & $0.61(0.19,1.98)$ & 0.41 & $0.86(0.26,2.80)$ & 0.81 \\
\hline \multicolumn{13}{|l|}{$\begin{array}{l}\text { FFMI } \\
\text { (kg/m2) }\end{array}$} \\
\hline Model I & 1 & 0.90 & $0.66(0.36,1.20)$ & 0.88 & $0.66(0.36,1.20)$ & 0.65 & 1 & 0.01 & $0.69(0.38,1.25)$ & 0.22 & $0.42(0.23,0.76)$ & 0.005 \\
\hline Model II & 1 & 0.15 & $0.84(0.44,1.57)$ & 0.1 & $0.90(0.47,1.71)$ & 0.09 & 1 & 0.17 & $0.88(0.47,1.67)$ & 0.71 & $0.55(0.28,1.06)$ & 0.07 \\
\hline Model III & 1 & 0.10 & $1.03(0.50,2.11)$ & 0.09 & $0.97(0.46,2.05)$ & 0.04 & 1 & 0.30 & $0.77(0.38,1.56)$ & 0.48 & $0.54(0.25,1.18)$ & 0.12 \\
\hline \multicolumn{13}{|l|}{ PBF (\%) } \\
\hline Model I & 1 & 0.29 & $1.00(0.55,1.80)$ & 0.17 & $1.09(0.60,1.96)$ & 0.17 & 1 & 0.90 & $0.95(0.53,1.72)$ & 0.88 & $0.87(0.48,1.57)$ & 0.65 \\
\hline Model II & 1 & 0.86 & $1.23(0.59,2.55)$ & 0.58 & $1.57(0.73,3.24)$ & 0.75 & 1 & 0.69 & $1.36(0.65,2.83)$ & 0.40 & $1.12(0.53,2.35)$ & 0.75 \\
\hline Model III & 1 & 0.98 & $1.40(0.64,3.06)$ & 0.93 & $1.77(0.80,3.91)$ & 0.95 & 1 & 0.68 & $1.27(0.56,2.87)$ & 0.56 & $1.46(0.61,3.47)$ & 0.39 \\
\hline
\end{tabular}

ED1, energy density from foods only; ED2, energy density from foods and all beverages; WHR, waist to hip ratio; FMI, fat mass index $=($ weight $\times$ PBF)/height; FFMI, fat-free mass index $=[$ weight $-($ weight $\times P B F)] /$ eight; PBF, percentage body fat calculated using sex-specific equations. Results are presented as OR and $95 \% \mathrm{Cls} .{ }^{*} \mathrm{Obesity:} \mathrm{BMI} \geq 30.0 \mathrm{~kg} / \mathrm{m}^{2} .{ }^{*} \mathrm{Model}$ I: crude. ${ }^{\dagger}$ Model II: adjusted for age and sex. ${ }^{+\dagger}$ Model III: adjusted for age, sex, marital status, menopause, physical activity, education, occupation, smoking status, chronic disease, and supplementation. §Overweight: BMI 25-29.9 kg/m². \|Abdominal obesity: defined as $W C \geq 102 \mathrm{~cm}$ for men and $\geq 88 \mathrm{~cm}$ for women. $p<0.05$ was considered significant.

patterns, we need more studies to find the right relationship between DED and body composition components (12). For example, in Asian populations, DED contains foods high in water (such as rice, noodles, and fish and shellfish), whereas in western countries with a lower intake of energy-dense foods (such as fats and oils, sugar, and confectionery) (10, 40, 49). However, it should be noted that the calculation methods are comparable when their food items were the same. In that case, their comparison is correct. Because the DED obtained in this study are derived from the data collected in this population, it is not expected that these EDs will be true in a population with different eating habits.

We found that lower ED was related to favorable dietary intake patterns for participants during this study, including a higher amount of fruits, vegetables, and a lower intake of total energy, carbohydrate, fat and oils, SFA, sodium, and red meat. In this 
regard, several studies showed that diets with high ED have more refined grains, processed food, sugars, and fats and as a result, have low fruits, vegetables, and whole grains $(19,40,50,51)$. In our research, the mean of ED1 and ED2 was 1.34 and $0.89 \mathrm{kcal} / \mathrm{g}$, respectively. Like other studies in this area, in Iranian populations $(11,13,14)$, these results were noticeably under those results shown in western studies $(1.79-1.85 \mathrm{kcal} / \mathrm{g})(9,10,48,49,52)$. This means that subjects in this study generally consume a lowenergy-dense diet than the rating of DED definition. The diet in Middle Eastern countries is different from that in the USA, Europe, and also other parts of Asia. This could be because of higher consumption of fats and sugar in western countries vs. a higher intake of rice and traditional bread in eastern countries. It is important to note that low DED and high DED foods varied not only in the ED but also in the composition of fat, protein, carbohydrates, and grams of fiber. Therefore, it is likely that the effects observed may be due to these differences in nutritional properties between DED food and high DED food (53). Likewise, we found that lower DED was linked to a lower BMI, but FMI, FFMI, PBF, and WC were not found to differ statistically according to the tertiles of ED1 and ED2; however, an increasing trend was detected from the first to the last tertile of both ED1 and ED2. This could be related to the age of participants. Participants in the highest tertile were significantly older than the participants in the lowest tertile of ED1 and ED2. In general, during aging, $\mathrm{PBF}$ increases, and FFM, lean mass, and bone mineral density decrease. Moreover, the increase in FM is distributed more specifically in the abdominal region (54).

The exact mechanisms through which low DED decreased BMI have not yet been perfectly understood, but it has been hypothesized that eating low-energy-dense foods instead of foods higher in ED might enhance satiety and lead to a significantly reduced energy intake (50). Several studies have found that a diet with higher ED is associated with poor appetite control (55) and higher body weight $(48,56)$. The volume of food acts as a satiety indicator. Therefore, consuming foods with high ED increases energy intake $(57,58)$. In several clinical and laboratory studies, the relationship between energy-dense foods with appetite stimulation and satiety has been investigated. One study measured satiety from $240 \mathrm{kcal}$ of 38 common foods in the weight ranging from 38 to $625 \mathrm{~g}$, which showed that the satiety index is inversely related to the weight of foods consumed. Dense foods such as chocolate and cakes were less satiety than low-density foods such as boiled potatoes and fish (59). Another study examined the relationship between ED, satiety, and food pleasantness. Low-density foods were more satiety but less palatable, whereas high-density foods were less satiety and more palatable $(60,61)$. A small number of body weight measuring studies reported a small amount of weight gain at the end of high DED (62-65). In the two studies, a higher energy intake was associated with lower density $(66,67)$. In some studies, excessive energy intake was associated with higher consumption of highcalorie beverages (68). But it is not yet clear whether density will lead to weight gain or overeating (60).

This study has several strengths and limitations. In this study, abdominal obesity was evaluated in addition to WC, including WHR and WHtR. However, the general statistics of general and abdominal obesity were low. So, it is hard to find a connection. Despite finding a more accurate relationship, we performed our results based on different analyses (linear and logistic regression and comparison of means). Moreover, the adjustment for important confounders was the strength of this study. Furthermore, we use FFQ to assess dietary intake. Also, several limitations of this study warrant mention. Firstly, the cross-sectional nature of the study does not permit the assessment of causality owing to the uncertain temporality of the association. Only a prospective study would provide a better understanding of the relationship between DED and obesity. On the other hand, our sample size in this study was not sufficient for a definite conclusion. Therefore, our findings based on the small sample size in this study may not be generalizable to society.

\section{CONCLUSION}

In summary, the results of this study did not show a significant relationship between ED with abdominal obesity, FMI, and other indices and body composition components in both Iranian men and women. However, our findings confirmed the profound effects that a higher energy-dense diet was associated with lower quality. Due to the association between poor quality diets and chronic diseases such as cardiovascular disease, diabetes, and obesity, high ED diets may be a risk factor. Further well-designed studies are required to investigate the exact link between DED and body composition.

\section{DATA AVAILABILITY STATEMENT}

The raw data supporting the conclusions of this article will be made available by the authors, without undue reservation.

\section{ETHICS STATEMENT}

The studies involving human participants were reviewed and approved by Ethical Committee of the Tehran University of Medical Sciences (Ethic Number: IR.TUMS.VCR.REC.1396.4085). The patients/participants provided their written informed consent to participate in this study.

\section{AUTHOR CONTRIBUTIONS}

EB and SS-B contributed to the design of this research. NB, SD, and $\mathrm{ME}$ contributed to the acquisition and interpretation of the data. EB did analysis. EB, SP, and SN drafted the manuscript. KD, SS-B, and LA critically revised the manuscript. SS-B supervised the study. All authors read and approved the final manuscript.

\section{ACKNOWLEDGMENTS}

We would like to acknowledge all participants who made this research possible. 


\section{REFERENCES}

1. Mazzoccoli G. Body composition: WHERE and when. Eur J Radiol. (2016) 85:1456-60. doi: 10.1016/j.ejrad.2015.10.020

2. Janssen I, Katzmarzyk PT, Ross R. Waist circumference and not body mass index explains obesity-related health risk. Am J Clin Nutr. (2004) 79:379-84. doi: 10.1093/ajen/79.3.379

3. Reeder BA, Senthilselvan A, Despres JP, Angel A, Liu L, Wang H, et al. The association of cardiovascular disease risk factors with abdominal obesity in Canada. Can Heart Health Surv Res Group Cmaj. (1997) 157:S39-45.

4. Kyle UG, Morabia A, Schutz Y, Pichard C. Sedentarism affects body fat mass index and fat-free mass index in adults aged 18 to 98 years. Nutrition. (2004) 20:255-60. doi: 10.1016/j.nut.2003.11.019

5. Gallagher D, Heymsfield SB, Heo M, Jebb SA, Murgatroyd PR, Sakamoto Y. Healthy percentage body fat ranges: an approach for developing guidelines based on body mass index. Am J Clin Nutr. (2000) 72:694-701. doi: 10.1093/ajcn/72.3.694

6. Iqbal SI, Helge JW, Heitmann BL. Do energy density and dietary fiber influence subsequent 5-year weight changes in adult men and women? Obesity. (2006) 14:106-14. doi: 10.1038/oby.2006.13

7. Ello-Martin JA, Ledikwe JH, Rolls BJ. The influence of food portion size and energy density on energy intake: implications for weight management. Am J Clin Nutr. (2005) 82:236s-41s. doi: 10.1093/ajcn.82.1.236S

8. Johnson L, Wilks DC, Lindroos AK, Jebb SA. Reflections from a systematic review of dietary energy density and weight gain: is the inclusion of drinks valid? Obes Rev. (2009) 10:681-92. doi: 10.1111/j.1467-789X.2009.00580.x

9. Mendoza JA, Drewnowski A. Christakis DA. Dietary energy density is associated with obesity and the metabolic syndrome in US adults. Diabetes Care. (2007) 30:974-9. doi: 10.2337/dc06-2188

10. Ledikwe JH, Blanck HM, Kettel Khan L, Serdula MK, Seymour JD, Tohill BC, et al. Dietary energy density is associated with energy intake and weight status in US adults. Am J Clin Nutr. (2006) 83:1362-8. doi: 10.1093/ajcn/83.6.1362

11. Shahinfar H, Safabakhsh M, Mansouri S, Djafarian K, Clark CCT, Shab-Bidar S. Association of dietary energy density with cardiometabolic risk factors and metabolic syndrome in Tehranian older adults. J Cardiovasc Thorac Res. (2020) 12:97-105. doi: 10.34172/jcvtr.2020.17

12. Azadbakht L, Haghighatdoost F, Keshteli AH, Larijani B, Esmaillzadeh A. Consumption of energy-dense diets in relation to metabolic syndrome and inflammatory markers in Iranian female nurses. Public Health Nutr. (2017) 20:893-901. doi: 10.1017/S1368980016002822

13. Esmaillzadeh A, Azadbakht L. Dietary energy density and the metabolic syndrome among Iranian women. Eur J Clin Nutr. (2011) 65:598-605. doi: 10.1038/ejcn.2010.284

14. Esmaillzadeh A, Boroujeni HK, Azadbakht L. Consumption of energy-dense diets in relation to cardiometabolic abnormalities among Iranian women. Public Health Nutr. (2012) 15:868-75. doi: 10.1017/S1368980011002680

15. Yin J, Xue HM, Chen YY, Zhang X, Quan LM, Gong YH, et al. Dietary energy density is positively associated with body composition of adults in Southwest China. Public Health Nutr. (2018) 21:1827-34. doi: $10.1017 /$ S1368980018000277

16. Howarth NC, Murphy SP, Wilkens LR, Hankin JH, Kolonel LN. Dietary energy density is associated with overweight status among 5 ethnic groups in the multiethnic cohort study. J Nutr. (2006) 136:2243-8. doi: $10.1093 / \mathrm{jn} / 136.8 .2243$

17. Savage JS, Marini M, Birch LL. Dietary energy density predicts women's weight change over 6 y. Am J Clin Nutr. (2008) 88:677-84. doi: 10.1093/ajcn/88.3.677

18. Bes-Rastrollo M, van Dam RM, Martinez-Gonzalez MA Li TY, Sampson LL, Hu FB. Prospective study of dietary energy density and weight gain in women. Am J Clin Nutr. (2008) 88:769-77. doi: 10.1093/ajcn/88.3.769

19. Ello-Martin JA, Roe LS, Ledikwe JH, Beach AM, Rolls BJ. Dietary energy density in the treatment of obesity: a year-long trial comparing 2 weight-loss diets. Am J Clin Nutr. (2007) 85:1465-77. doi: 10.1093/ajcn/85.6.1465

20. Saquib N, Natarajan L, Rock CL, Flatt SW, Madlensky L, Kealey S, et al. The impact of a long-term reduction in dietary energy density on body weight within a randomized diet trial. Nutr Cancer. (2008) 60:31-8. doi: 10.1080/01635580701621320

21. de Castro JM. Dietary energy density is associated with increased intake in free-living humans. J Nutr. (2004) 134:335-41. doi: 10.1093/jn/134.2.335
22. Grossniklaus DA, Dunbar SB, Gary R, Tohill BC, Frediani JK, Higgins MK Dietary energy density: a mediator of depressive symptoms and abdominal obesity or independent predictor of abdominal obesity? Eur J Cardiovasc Nurs. (2012) 11:423-31. doi: 10.1016/j.ejcnurse.2011.03.008

23. de Castro JM. Stomach filling may mediate the influence of dietary energy density on the food intake of free-living humans. Physiol Behav. (2005) 86:32-45. doi: 10.1016/j.physbeh.2005.06.032

24. Maddahi NS, Yarizadeh H, Setayesh L, Nasir Y, Alizadeh S, Mirzaei K. Association between dietary energy density with mental health and sleep quality in women with overweight/obesity. BMC Res Notes. (2020) 13:189. doi: 10.1186/s13104-020-05025-1

25. Azadbakht L, Haghighatdoost F, Esmaillzadeh A. Dietary energy density is inversely associated with the diet quality indices among Iranian young adults. J Nutr Sci Vitaminol. (2012) 58:29-35. doi: 10.3177/jnsv.58.29

26. Daneshzad E, Dorosty-Motlagh A, Bellissimo N, Suitor K, Azadbakht L. Food insecurity, dietary acid load, dietary energy density and anthropometric indices among Iranian children. Eat Weight Disord. (2020) 26:839-46. doi: 10.1007/s40519-020-00921-8

27. Esfahani FH, Asghari G, Mirmiran P, Azizi F. Reproducibility and relative validity of food group intake in a food frequency questionnaire developed for the Tehran Lipid and Glucose Study. J Epidemiol. (2010) 20:150-8. doi: 10.2188/jea.JE20090083

28. Sadeghi O, Sadeghi A, Mozaffari-Khosravi H, Shokri A. The association between nutrient patterns and metabolic syndrome among Iranian adults: cross-sectional analysis of Shahedieh cohort study. Public Health Nutr. 2020:1-10. doi: 10.1017/S1368980020001639

29. Ledikwe JH, Blanck HM, Khan LK, Serdula MK, Seymour JD, Tohill BC, et al. Dietary energy density determined by eight calculation methods in a nationally representative United States population. J Nutr. (2005) 135:273-8. doi: $10.1093 / \mathrm{jn} / 135.2 .273$

30. Organization WH. Waist circumference and waist-hip ratio: report of a WHO expert consultation, Geneva. (2011) (accessed December 8-11, 2008).

31. Committee IR, Guidelines for data processing and analysis of the International Physical Activity Questionnaire (IPAQ)-short and long forms. www.ipaq.ki.se. (2005) Committee, I.R., Guidelines for data processing and analysis of the International Physical Activity Questionnaire (IPAQ)-short and long forms. www.ipaq.ki.se Available online at: (2005) Committee, I.R., Guidelines for data processing and analysis of the International Physical Activity Questionnaire (IPAQ)-short and long forms. www.ipaq.ki.se. (2005)

32. Ainsworth BE, Haskell WL, Herrmann SD, Meckes N, Bassett Jr DR, TudorLocke C, et al. 2011 Compendium of Physical Activities: a second update of codes and MET values. Med Sci Sports Exercise. (2011) 43:1575-81. doi: 10.1249/MSS.0b013e31821ece12

33. Wareham NJ, Jakes RW, Rennie KL, Schuit J, Mitchell J, Hennings S, et al. Validity and repeatability of a simple index derived from the short physical activity questionnaire used in the European Prospective Investigation into Cancer and Nutrition (EPIC) study. Public Health Nutr. (2003) 6:407-13. doi: 10.1079/PHN2002439

34. Tordoff MG, Alleva AM. Effect of drinking soda sweetened with aspartame or high-fructose corn syrup on food intake and body weight. Am J Clin Nutr. (1990) 51:963-9. doi: 10.1093/ajcn/51.6.963

35. DiMeglio DP, Mattes RD. Liquid versus solid carbohydrate: effects on food intake and body weight. I Int J Obes Relat Metab Disord. (2000) 24:794-800. doi: $10.1038 /$ sj.ijo.0801229

36. van Sluijs EM, Sharp SJ, Ambrosini GL, Cassidy A, Griffin SJ, Ekelund U. The independent prospective associations of activity intensity and dietary energy density with adiposity in young adolescents. Br J Nutr. (2016) 115:921-9. doi: 10.1017/S0007114515005097

37. Marchioni D, Gorgulho B, Lipi M, Previdelli A. Energy density and diet quality among Brazilian workers. Nutr Food Sci. (2013) 43:422-31. doi: 10.1108/NFS-04-2012-0035

38. Stookey JD. Energy density, energy intake and weight status in a large freeliving sample of Chinese adults: exploring the underlying roles of fat, protein, carbohydrate, fiber and water intakes. Eur J Clin Nutr. (2001) 55:349-59. doi: $10.1038 /$ sj.ejcn. 1601163

39. Sasaki KM, Wada K, Zeredo JLL, Nagata C. Prospective study of dietary energy density and weight gain in a Japanese adult population. Br J Nutr. (2017) 117:822-8. doi: 10.1017/S0007114517000484 
40. Murakami K, Livingstone MB, Okubo H, Sasaki S. Energy density of the diets of Japanese adults in relation to food and nutrient intake and general and abdominal obesity: a cross-sectional analysis from the 2012 National Health and Nutrition Survey, Japan. Br J Nutr. (2017) 117:161-9. doi: $10.1017 /$ S0007114516004451

41. Du H. van der AD, Ginder V, Jebb SA, Forouhi NG, Wareham NJ, et al. Dietary energy density in relation to subsequent changes of weight and waist circumference in European men and women. PLoS One. (2009) 4:e5339. doi: 10.1371/journal.pone.0005339

42. Correa-Rodriguez M, Gonzalez-Jimenez E, Fernandez-Aparicio A, Luis Gomez-Urquiza J, Schmidt-RioValle J, Rueda-Medina B. Dietary energy density is associated with body mass index and fat mass in early adulthood. Clin Nurs Res. (2019) 2019:1054773819883192. doi: $10.1177 / 1054773819883192$

43. Rouhani MH, Surkan PJ, Azadbakht L. The effect of preload/meal energy density on energy intake in a subsequent meal: a systematic review and meta-analysis. Eat Behav. (2017) 26:6-15. doi: 10.1016/j.eatbeh.2016.12.011

44. Stelmach-Mardas M, Rodacki T, Dobrowolska-Iwanek J, Brzozowska A, Walkowiak J, Wojtanowska-Krosniak A, et al. Link between food energy density and body weight changes in obese adults. Nutrients. (2016) 8:229. doi: 10.3390/nu8040229

45. Perez-Escamilla R, Obbagy JE, Altman JM, Essery EV, McGrane MM, Wong YP, et al. Dietary energy density and body weight in adults and children: a systematic review. J Acad Nutr Diet. (2012) 112:671-84. doi: 10.1016/j.jand.2012.01.020

46. Vergnaud AC, Estaquio C, Czernichow S, Peneau S, Hercberg S, Galan P, et al. Energy density and 6-year anthropometric changes in a middle-aged adult cohort. Br J Nutr. (2009) 102:302-9. doi: 10.1017/S0007114508162109

47. Livingstone MB, Black AE. Markers of the validity of reported energy intake. J Nutr. (2003) 133:895s-920s. doi: 10.1093/jn/133.3.895S

48. Vernarelli JA, Mitchell DC, Rolls BJ, Hartman TJ. Dietary energy density is associated with obesity and other biomarkers of chronic disease in US adults. Eur J Nutr. (2015) 54:59-65. doi: 10.1007/s00394-014-0685-0

49. Kant AK, Graubard BI. Energy density of diets reported by American adults: association with food group intake, nutrient intake, and body weight. Int J Obesity. (2005) 29:950-6. doi: 10.1038/sj.ijo.0802980

50. Rolls BJ. The relationship between dietary energy density and energy intake. Physiol Behav. (2009) 97:609-15. doi: 10.1016/j.physbeh.2009.03.011

51. Patterson E, Warnberg J, Poortvliet E, Kearney JM, Sjostrom M. Dietary energy density as a marker of dietary quality in Swedish children and adolescents: the European Youth Heart Study. Eur J Clin Nutr. (2010) 64:35663. doi: $10.1038 /$ ejen.2009.160

52. O'Connor L, Walton J, Flynn A. Dietary energy density: estimates, trends and dietary determinants for a nationally representative sample of the Irish population (aged 5-90 years). Br J Nutr. (2015) 113:172-80. doi: 10.1017/S0007114514003420

53. Buckland NJ, Camidge D, Croden F, Myers A, Lavin JH, Stubbs RJ, et al. Women with a low-satiety phenotype show impaired appetite control and greater resistance to weight loss. Br J Nutr. (2019) 122:951-9. doi: 10.1017/S000711451900179X

54. St-Onge MP, Gallagher D. Body composition changes with aging: the cause or the result of alterations in metabolic rate and macronutrient oxidation? Nutrition. (2010) 26:152-5. doi: 10.1016/j.nut.2009.07.004

55. Latner JD, Rosewall JK, Chisholm AM. Energy density effects on food intake, appetite ratings, and loss of control in women with binge eating disorder and weight-matched controls. Eat Behav. (2008) 9:257-66. doi: 10.1016/j.eatbeh.2007.09.002

56. Vernarelli JA, Mitchell DC, Hartman TJ. Rolls BJ. Dietary energy density is associated with body weight status and vegetable intake in US children. $J$ Nutrit. (2011) 141:2204-10. doi: 10.3945/jn.111.146092
57. McCrory MA, Saltzman E, Rolls BJ, Roberts SB, A. twin study of the effects of energy density and palatability on energy intake of individual foods. Physiol Behav. (2006) 87:451-9. doi: 10.1016/j.physbeh.2004.10.025

58. Rolls BJ, Drewnowski A, Ledikwe JH. Changing the energy density of the diet as a strategy for weight management. J Am Dietet Assoc. (2005) 105:S98-103. doi: 10.1016/j.jada.2005.02.033

59. Holt SH, Miller JC, Petocz P, Farmakalidis E. A satiety index of common foods. Eur J Clin Nutr. (1995) 49:675-90.

60. Drewnowski A, Almiron-Roig E, Marmonier C, Lluch A. Dietary energy density and body weight: is there a relationship? Nutr Rev. (2004) 62:403-13. doi: 10.1111/j.1753-4887.2004.tb00012.x

61. Drewnowski A. Taste preferences and food intake. Annu Rev Nutr. (1997) 17:237-53. doi: 10.1146/annurev.nutr.17.1.237

62. Olin AO, Osterberg P, Hadell K, Armyr I, Jerstrom S, Ljungqvist O. Energyenriched hospital food to improve energy intake in elderly patients. JPEN. (1996) 20:93-7. doi: 10.1177/014860719602000293

63. Brown KH, Sanchez-Grinan M, Perez F, Peerson JM, Ganoza L, Stern JS. Effects of dietary energy density and feeding frequency on total daily energy intakes of recovering malnourished children. Am J Clin Nutr. (1995) 62:13-8. doi: $10.1093 /$ ajcn/62.1.13

64. Stubbs RJ, Johnstone AM, Harbron CG, Reid C. Covert manipulation of energy density of high carbohydrate diets in 'pseudo free-living' humans. Int J Obesity Relat Metabol Diso. (1998) 22:885-92. doi: 10.1038/sj.ijo.0800676

65. Stubbs RJ, Johnstone AM, O'Reilly LM, Barton K, Reid C. The effect of covertly manipulating the energy density of mixed diets on ad libitum food intake in 'pseudo free-living' humans. Int J Obes Relat Metab Diso. (1998) 22:980-7. doi: 10.1038/sj.ijo.0800715

66. Araya H, Vera G, Alvina M. Effect of the energy density and volume of high carbohydrate meals on short term satiety in preschool children. Eur J Clin Nutr. (1999) 53:273-6. doi: 10.1038/sj.ejcn.1600721

67. Durrant ML, Royston JP, Wloch RT, Garrow JS. The effect of covert changes in energy density of preloads on subsequent ad libitum energy intake in lean and obese human subjects. Human Nutr Clin Nutr. (1982) 36:297-306.

68. Raben A, Vasilaras TH, Møller AC, Astrup A. Sucrose compared with artificial sweeteners: different effects on ad libitum food intake and body weight after 10 wk of supplementation in overweight subjects. Am J Clin Nutr. (2002) 76:721-9. doi: 10.1093/ajen/76.4.721

Conflict of Interest: The authors declare that the research was conducted in the absence of any commercial or financial relationships that could be construed as a potential conflict of interest.

The reviewer YJ declared a shared affiliation with the authors to the handling editor at the time of the review.

Publisher's Note: All claims expressed in this article are solely those of the authors and do not necessarily represent those of their affiliated organizations, or those of the publisher, the editors and the reviewers. Any product that may be evaluated in this article, or claim that may be made by its manufacturer, is not guaranteed or endorsed by the publisher.

Copyright (C) 2021 Bazshahi, Pourreza, Imani, Azadbakht, Ebaditabar, Davarzani, Babaei, Naghshi, Djafarian and Shab-Bidar. This is an open-access article distributed under the terms of the Creative Commons Attribution License (CC BY). The use, distribution or reproduction in other forums is permitted, provided the original author(s) and the copyright owner(s) are credited and that the original publication in this journal is cited, in accordance with accepted academic practice. No use, distribution or reproduction is permitted which does not comply with these terms. 